\title{
Association between ERCC5 gene polymorphisms and gastric cancer risk in a Chinese population
}

\author{
R.J. Li, M. Li, G.J. Liu, Y.W. Guo, H. Bai, P. Xiao and J.Z. Mei \\ Department of Medical Oncology, Zhengzhou People's Hospital, Zhengzhou, China \\ Corresponding author: J.Z. Mei \\ E-mail: jiangtbt@163.com \\ Genet. Mol. Res. 15 (1): gmr.15017510 \\ Received August 24, 2015 \\ Accepted December 3, 2015 \\ Published March 31, 2016 \\ DOI http://dx.doi.org/10.4238/gmr.15017510
}

\begin{abstract}
We conducted a hospital-based case-control study to investigate the association between 3 common SNPs in the ERCC5 gene (rs1047768, rs751402, and rs17655) and the risk of developing gastric cancer. Between January 2013 and December 2014, samples were collected from 216 gastric cancer patients and 216 control subjects. ERCC5 rs1047768, rs751402, and rs17655 polymorphisms were genotyped by polymerase chain reaction combined with restriction fragment length polymorphism analysis. By conditional logistic regression analysis, the GG genotype of rs17655 was found to be associated with an elevated risk of gastric cancer in a codominant model, and the adjusted OR $(95 \% \mathrm{Cl})$ was 1.96 (1.10-3.50). Moreover, in a dominant model, the CG + GG genotype of rs17655 was correlated with an increased risk of gastric cancer compared to the CC genotype $(\mathrm{OR}=1.48 ; 95 \% \mathrm{Cl}=1.00-2.22) . \mathrm{rs} 1047768$ and rs751402 were not significantly correlated with an increased or decreased gastric cancer risk.
\end{abstract}

Key words: ERCC5; Polymorphism; Gastric cancer 


\section{INTRODUCTION}

Almost one million new cases of gastric cancer are estimated to have been diagnosed in 2012 (952,000 cases, $6.8 \%$ of the total gastric cancer cases), making it the fifth most common malignancy in the world (IARC, 2012). More than $70 \%$ of cases $(677,000$ cases) occur in developing countries (456,000 in men, 221,000 in women), and half of the world total occurs in Eastern Asia (mainly in China) (IARC, 2012). The development of gastric cancer is correlated with various risk factors, including genetic predisposition, environmental factors, and microbial infections (Ang and Fock, 2014; Daniyal et al., 2015; Fang et al., 2015). Helicobacter pylori infection, for example, is an important risk factor for the development of gastric cancer (Graham and Yamaoka, 2000; Ang and Fock, 2014; Fang et al., 2015), but several single nucleotide polymorphisms (SNPs) are also associated with gastric carcinogenesis (Kamangar et al., 2006; Yuzhalin, 2011).

ERCC5, or 'excision repair cross-complementing rodent repair deficiency, complementation group 5', encodes an important member of a family of enzymes, which function in nucleotide excision repair (NER). The ERCC5 gene covers the DNaselV/flap structure-specific endonuclease 1 (FEN1) group of structure-specific nucleases (Hohl et al., 2007). Recently, genetic polymorphisms of genes involved in multiple-biological pathways, including DNA repair, have been identified as important risk factors for gastric cancer (McCullough et al., 2014). Here, we conducted a case-control study to investigate the association between 3 common SNPs in the ERCC5 gene (rs1047768, rs 751402 and rs17655) and gastric cancer risk.

\section{MATERIAL AND METHODS}

\section{Study population}

For our hospital-based case-control designed study, we recruited 216 patients who were newly diagnosed with histopathologically confirmed primary gastric cancer at Zhengzhou People's Hospital between January 2013 and December 2014. Patients who had primary tumors other than gastric cancer, tumors of an unknown origin, or any histopathological diagnosis other than gastric cancer were excluded.

A total of 216 controls were randomly selected from individuals who received health check-ups in our hospital, and the controls were matched with the patients with gastric cancer by gender and age ( \pm 5 years). Subjects with any type of digestive disease, including atrophic gastritis, inflammation, hyperplasia, and intestinal metaplasia, were excluded.

The demographic characteristics, including gender, age, alcohol consumption, and smoking status, were collected using a self-designed questionnaire. The clinical characteristics, including histological types and TNM stage, were collected from medical records. $H$. pylori infections were detected by serology, histological examination, or the urea breath test. Written informed consent was obtained from each participant prior to the study. The study was approved by the Institutional Research Ethics Committee of Zhengzhou People's Hospital.

\section{DNA extraction and genotyping}

A 2-mL sample of peripheral blood was collected from all patients and control subjects and stored at $4^{\circ} \mathrm{C}$. Genomic DNA was extracted using the QIAamp DNAMAX Kit (Qiagen, Hilden, Germany). 
ERCC5 rs1047768, rs751402, and rs17655 polymorphisms were genotyped by polymerase chain reaction $(\mathrm{PCR})$ combined with restriction fragment length polymorphism analysis. The primers were designed using the Sequenom Assay Design 3.1 software. The samples were amplified using the following conditions: an initial denaturation at $95^{\circ} \mathrm{C}$ for $5 \mathrm{~min}, 30$ cycles of annealing at $62^{\circ} \mathrm{C}$ for 60 $\mathrm{s}$ and extension at $72^{\circ} \mathrm{C}$ for $60 \mathrm{~s}$, and a final extension at $72^{\circ} \mathrm{C}$ for $10 \mathrm{~min}$. The PCR products were analyzed with ultraviolet light on a $2 \%$ agarose gel after ethidium bromide staining.

\section{Statistical analysis}

Continuous variables are reported as means \pm standard deviation (SD), and categorical variables are reported as frequencies and percentages of study subjects. Differences in the demographic characteristics between the two groups were analyzed using the chi-square test or the Student $t$-test. The Hardy-Weinberg equilibrium (HWE) in controls was evaluated using the Fisher exact test. The role of ERCC5 rs1047768, rs751402, and rs17655 polymorphisms in the development of gastric cancer was evaluated by conditional logistic regression, and the results are reported as ORs and $95 \% \mathrm{Cls}$. All $\mathrm{P}$ values were two-sided, and $\mathrm{P}<0.05$ was considered to be statistically significant. All statistical analyses were performed using the SPSS statistical software package, version 16.0 (SPSS Inc., Chicago, IL, USA).

\section{RESULTS}

The distributions of the demographic and clinical characteristics of gastric cancer patients and control subjects are presented in Table 1. Compared to the controls, patients with gastric cancer were more likely to be infected by $H$. pylori. However, no statistically significant differences were found between patients with gastric cancer and control subjects in terms of gender, age, alcohol drinking, or tobacco smoking at interview. Of the 216 patients with gastric cancer, 90 patients were diagnosed with the intestinal type and 126 with the diffuse type. Ninety-seven patients were I-II TNM stage and 119 III-IV TNM stage.

Table 1. Demographic and clinical characteristics of patients with gastric cancer and control subjects.

\begin{tabular}{|c|c|c|c|c|c|c|}
\hline Variables & Patients & $\%$ & Controls & $\%$ & $\chi^{2}$ test & $\mathrm{P}$ value \\
\hline \multicolumn{7}{|c|}{ Age (years) } \\
\hline$<55$ & 124 & 57.41 & 123 & 56.94 & & \\
\hline$\geq 60$ & 92 & 42.59 & 93 & 43.06 & 0.01 & 0.92 \\
\hline \multicolumn{7}{|l|}{ Gender } \\
\hline Female & 71 & 32.87 & 71 & 32.87 & & \\
\hline Male & 145 & 67.13 & 145 & 67.13 & $<0.001$ & 1.00 \\
\hline \multicolumn{7}{|c|}{ Alcohol drinkers } \\
\hline Never & 102 & 47.22 & 122 & 56.48 & & \\
\hline Ever & 114 & 52.78 & 94 & 43.52 & 3.71 & 0.05 \\
\hline \multicolumn{7}{|c|}{ Tobacco smoking } \\
\hline Never & 115 & 53.24 & 125 & 57.87 & & \\
\hline Ever & 101 & 46.76 & 91 & 42.13 & 0.94 & 0.33 \\
\hline \multicolumn{7}{|c|}{ Helicobacter pylori } \\
\hline Negative & 89 & 41.20 & 144 & 66.67 & & \\
\hline Positive & 127 & 58.80 & 72 & 33.33 & 28.18 & $<0.001$ \\
\hline \multicolumn{7}{|c|}{ Lauren's classification } \\
\hline Intestinal & 90 & 41.67 & & & & \\
\hline Diffuse & 126 & 58.33 & & & & \\
\hline \multicolumn{7}{|l|}{ TNM stage } \\
\hline$|-| \mid$ & 97 & 44.91 & & & & \\
\hline III-IV & 119 & 55.09 & & & & \\
\hline
\end{tabular}


Using the Fisher exact test, the genotype distributions of rs751402 and rs17655 were in Hardy-Weinberg equilibrium in control subjects, but rs1047768 was not (Table 2). Moreover, the minor allele frequencies of the 3 SNPs were similar to those in dbSNP.

Table 2. Information on the 3 SNPs in ERCC5.
\begin{tabular}{l|l|l|c|c|c}
\hline SNPs & Base change & SNP location & Hardy-Weinberg equilibrium & \multicolumn{2}{c}{ Minor allele frequencies } \\
\cline { 3 - 6 } & & & 0.004 & In database & In controls \\
\hline rs1047768 & T $>$ C & Exon & 0.4930 & 0.4837 \\
\hline rs751402 & G $>$ A & Promoter & 0.3111 & 0.3218 \\
\hline rs17655 & C $>$ G & Exon & 0.3614 & 0.3565 \\
\hline
\end{tabular}

The correlations between the 3 SNPs in ERCC5 and gastric cancer risk are shown in Table 3. By conditional logistic regression analysis, the GG genotype of rs 17655 was found to be associated with an elevated risk of gastric cancer in a codominant model, and the adjusted OR $(95 \% \mathrm{Cl})$ was 1.96 (1.10-3.50). Moreover, in the dominant model, the $C G+G G$ genotype of rs17655 was correlated with an increased risk of gastric cancer compared to the CC genotype (OR $=1.48 ; 95 \% \mathrm{Cl}=1.00-2.22$ ). However, in the recessive model, the GG genotype of rs17655 was not associated with an increased risk of gastric cancer when compared with the CC + CG genotype $(\mathrm{OR}=1.54,95 \% \mathrm{Cl}=0.91-2.63) . \mathrm{rs} 1047768$ and $\mathrm{rs} 751402$ showed no significant correlation with gastric cancer development.

Table 3. Association between ERCC5 polymorphisms and gastric cancer risk.

\begin{tabular}{|c|c|c|c|c|c|c|c|c|}
\hline ERCC5 & Cases & $\%$ & Controls & $\%$ & $\chi^{2}$ test & $P$ value & OR $(95 \% \mathrm{Cl})^{1}$ & $P$ value \\
\hline \multicolumn{9}{|c|}{ rs1047768 } \\
\hline \multicolumn{9}{|c|}{ Codominant } \\
\hline$T T$ & 57 & 26.39 & 68 & 31.48 & & & 1.0 (Ref.) & - \\
\hline$T C$ & 92 & 42.59 & 87 & 40.28 & & & $1.26(0.78-2.05)$ & 0.32 \\
\hline$C C$ & 67 & 31.02 & 61 & 28.24 & 1.39 & 0.50 & $1.31(0.78-2.21)$ & 0.28 \\
\hline \multicolumn{9}{|c|}{ Dominant } \\
\hline$T T$ & 57 & 26.39 & 68 & 31.48 & & & 1.0 (Ref.) & - \\
\hline$T C+C C$ & 159 & 73.61 & 148 & 68.52 & 1.39 & 0.24 & $1.28(0.83-1.99)$ & 0.24 \\
\hline \multicolumn{9}{|c|}{ Recessive } \\
\hline$T T+T C$ & 149 & 68.98 & 155 & 71.76 & & & 1.0 (Ref.) & - \\
\hline$C C$ & 67 & 31.02 & 61 & 28.24 & 0.40 & 0.53 & $1.14(0.74-1.77)$ & 0.53 \\
\hline \multicolumn{9}{|c|}{ rs751402 } \\
\hline \multicolumn{9}{|c|}{ Codominant } \\
\hline CC & 88 & 40.74 & 95 & 43.98 & & & 1.0 (Ref.) & \\
\hline$C T$ & 106 & 49.07 & 103 & 47.69 & & & $1.11(0.73-1.69)$ & 0.60 \\
\hline$T T$ & 22 & 10.19 & 18 & 8.33 & 0.71 & 0.70 & $1.32(0.63-2.80)$ & 0.43 \\
\hline \multicolumn{9}{|c|}{ Dominant } \\
\hline CC & 88 & 40.74 & 95 & 43.98 & & & 1.0 (Ref.) & - \\
\hline$C T+T T$ & 128 & 59.26 & 121 & 56.02 & 0.46 & 0.50 & $1.14(0.77-1.70)$ & 0.50 \\
\hline \multicolumn{9}{|c|}{ Recessive } \\
\hline$C C+C T$ & 194 & 89.81 & 198 & 91.67 & & & 1.0 (Ref.) & - \\
\hline$T T$ & 22 & 10.19 & 18 & 8.33 & 0.44 & 0.51 & $1.25(0.62-2.55)$ & 0.51 \\
\hline \multicolumn{9}{|l|}{ rs17655 } \\
\hline \multicolumn{9}{|c|}{ Codominant } \\
\hline$C C$ & 72 & 33.33 & 94 & 43.52 & & & 1.0 (Ref.) & \\
\hline$C G$ & 96 & 44.44 & 90 & 41.67 & & & $1.39(0.89-2.17)$ & 0.12 \\
\hline GG & 48 & 22.22 & 32 & 14.81 & 6.31 & 0.04 & $1.96(1.10-3.50)$ & 0.01 \\
\hline \multicolumn{9}{|c|}{ Dominant } \\
\hline$C C$ & 75 & 34.72 & 94 & 43.52 & & & 1.0 (Ref.) & - \\
\hline$C G+G G$ & 144 & 66.67 & 122 & 56.48 & 3.94 & 0.04 & $1.48(1.00-2.22)$ & 0.04 \\
\hline \multicolumn{9}{|c|}{ Recessive } \\
\hline$C C+C G$ & 168 & 77.78 & 184 & 85.19 & & & 1.0 (Ref.) & - \\
\hline GG & 45 & 20.83 & 32 & 14.81 & 2.90 & 0.09 & $1.54(0.91-2.63)$ & 0.09 \\
\hline
\end{tabular}

${ }^{1}$ Adjusted for gender, age, alcohol drinking, and Helicobacter pylori. 


\section{DISCUSSION}

In the present study, we investigated the impact of ERCC5 rs1047768, rs751402, and rs17655 polymorphisms on gastric cancer risk in a Chinese patient group. Our findings showed a significant association between ERCC5 rs17655 polymorphism and gastric cancer, so that GG as well as $C G+G G$ genotypes increased the risk of gastric cancer in comparison with the wild-type genotype. However, no significant association was found between the rs1047768 and rs751402 variants and gastric cancer.

ERCC5 belongs to the NER pathway genes, responsible for repairing DNA damage caused by environmental and biological mutagens, as well as by normal cellular metabolism. Unrepaired DNA damage leads to genetic mutations and can subsequently induce carcinogenesis (Weiss et al., 2006). Accumulating evidence suggests that ERCC5 deficiency promotes carcinogenesis, and causes DNA damage and genomic instability as well as gene transcription abnormality (Cheng et al., 2002; Koeppel et al., 2004; Bartolucci et al., 2009). Since changes in ERCC5 can alter the DNA repair function of this gene, they can lead to increased cancer susceptibility.

Previous studies have reported that the ERCC5 rs17655 polymorphism has important roles in the development of several kinds of cancer, such as colorectal cancer, uterine cervical cancer, lung cancer, laryngeal cancer, as well as breast cancer (Li et al., 2014; Liang et al., 2014; Joo et al., 2015; Na et al., 2015; Zeng et al., 2015). Li et al. (2014) reported that the ERCC5 rs17655 polymorphism is correlated with susceptibility to laryngeal cancer, while Joo et al. (2015) conducted a study in a Korean population, and found that it was associated with the development of cervical cancer. Zeng et al. (2015) conducted a meta-analysis of 9 studies, and found that this polymorphism might influence the development of colorectal cancer. In contrast, a previous metaanalysis of 44 published case-control studies reported that the ERCC5 rs17655 polymorphism did not influence cancer risk (Zhu et al., 2012).

Only two previous studies have reported the association between gastric cancer and the ERCC5 rs17655 polymorphism (Hussain et al., 2009; Xue et al., 2015). Hussain et al. (2009) have found that it contributes to the development of gastric cancer, however, Xue et al. (2015) conducted a study in a Chinese population and did not find a significant association. In this study, we did find an association between the ERCC5 rs 17655 polymorphism and the development of gastric cancer. Therefore, further studies are greatly needed to confirm these findings.

In conclusion, our study suggests that the ERCC5 rs 17655 polymorphism is associated with an increased risk of gastric cancer in a codominant and dominant models, and further investigation of the role of ERCC5 gene polymorphisms on the risk of gastric cancer are needed.

\section{Conflicts of interest}

The authors declare no conflict of interest.

\section{REFERENCES}

Ang TL and Fock KM (2014). Clinical epidemiology of gastric cancer. Singapore Med. J. 55: 621-628. http://dx.doi.org/10.11622/ smedj.2014174

Bartolucci R, Wei J, Sanchez JJ, Perez-Roca L, et al. (2009). XPG mRNA expression levels modulate prognosis in resected non-small-cell lung cancer in conjunction with BRCA1 and ERCC1 expression. Clin. Lung Cancer 10: 47-52. http://dx.doi. org/10.3816/CLC.2009.n.007 
Cheng L, Sturgis EM, Eicher SA, Spitz MR, et al. (2002). Expression of nucleotide excision repair genes and the risk for squamous cell carcinoma of the head and neck. Cancer 94: 393-397. http://dx.doi.org/10.1002/cncr.10231

Daniyal M, Ahmad S, Ahmad M, Asif HM, et al. (2015). Risk factors and epidemiology of gastric cancer in Pakistan. Asian Pac. J. Cancer Prev. 16: 4821-4824. http://dx.doi.org/10.7314/APJCP.2015.16.12.4821

Fang C, Huang Q, Lu L, Shi J, et al. (2015). Risk factors of early proximal gastric carcinoma in Chinese diagnosed using WHO criteria. J. Dig. Dis. 16: 327-336. http://dx.doi.org/10.1111/1751-2980.12240

Graham DY and Yamaoka Y (2000). Disease-specific Helicobacter pylori virulence factors: the unfulfilled promise. Helicobacter 5 (Suppl 1): S3-S9, discussion S27-S31. http://dx.doi.org/10.1046/j.1523-5378.2000.0050S1003.x

Hohl M, Dunand-Sauthier I, Staresincic L, Jaquier-Gubler P, et al. (2007). Domain swapping between FEN-1 and XPG defines regions in XPG that mediate nucleotide excision repair activity and substrate specificity. Nucleic Acids Res. 35: 30533063. http://dx.doi.org/10.1093/nar/gkm092

Hussain SK, Mu LN, Cai L, Chang SC, et al. (2009). Genetic variation in immune regulation and DNA repair pathways and stomach cancer in China. Cancer Epidemiol. Biomarkers Prev. 18: 2304-2309. http://dx.doi.org/10.1158/1055-9965.EPI$\underline{09-0233}$

International Agency for Research on Cancer (IARC) (2012). Stomach Cancer. Estimated Incidence, Mortality and Prevalence Worldwide in 2012. http://globocan.iarc.fr/Pages/fact_sheets_cancer.aspx. Accessed Aug 20, 2015.

Joo J, Yoon KA, Hayashi T, Kong SY, et al. (2015). Nucleotide Excision Repair Gene ERCC2 and 5 Variants Increase Risk of Uterine Cervical Cancer. Cancer Res. Treat. June: 22; epub ahead of print.

Kamangar F, Abnet CC, Hutchinson AA, Newschaffer CJ, et al. (2006). Polymorphisms in inflammation-related genes and risk of gastric cancer (Finland). Cancer Causes Control 17: 117-125. http://dx.doi.org/10.1007/s10552-005-0439-7

Koeppel F, Poindessous V, Lazar V, Raymond E, et al. (2004). Irofulven cytotoxicity depends on transcription-coupled nucleotide excision repair and is correlated with XPG expression in solid tumor cells. Clin. Cancer Res. 10: 5604-5613. http://dx.doi.org/10.1158/1078-0432.CCR-04-0442

Li X, Xu J, Yang X, Wu Y, et al. (2014). Association of single nucleotide polymorphisms of nucleotide excision repair genes with laryngeal cancer risk and interaction with cigarette smoking and alcohol drinking. Tumour Biol. 35: 4659-4665. http:// dx.doi.org/10.1007/s13277-014-1610-0

Liang Y, Deng J, Xiong Y, Wang S, et al. (2014). Genetic association between ERCC5 rs17655 polymorphism and lung cancer risk: evidence based on a meta-analysis. Tumour Biol. 35: 5613-5618. http://dx.doi.org/10.1007/s13277-014-1742-2

McCullough LE, Santella RM, Cleveland RJ, Millikan RC, et al. (2014). Polymorphisms in DNA repair genes, recreational physical activity and breast cancer risk. Int. J. Cancer 134: 654-663. http://dx.doi.org/10.1002/ijc.28383

Na N, Dun E, Ren L and Li G (2015). Association between ERCC5 gene polymorphisms and breast cancer risk. Int. J. Clin. Exp. Pathol. 8: 3192-3197.

Weiss JM, Weiss NS, Ulrich CM, Doherty JA, et al. (2006). Nucleotide excision repair genotype and the incidence of endometrial cancer: effect of other risk factors on the association. Gynecol. Oncol. 103: 891-896. http://dx.doi.org/10.1016/j. ygyno.2006.05.020

Xue MH, Li GY, Wu XJ, Zhang CX, et al. (2015). Genetic variability of genes in NER pathway influences the treatment outcome of gastric cancer. Int. J. Clin. Exp. Pathol. 8: 5563-5569.

Yuzhalin A (2011). The role of interleukin DNA polymorphisms in gastric cancer. Hum. Immunol. 72: 1128-1136. http://dx.doi. org/10.1016/j.humimm.2011.08.003

Zeng Y, Wei L, Wang YJ and Liu C (2015). Genetic Association between ERCC5 rs17655 Polymorphism and Colorectal Cancer Risk: Evidence Based on a Meta-analysis. Asian Pac. J. Cancer Prev. 16: 5565-5571. http://dx.doi.org/10.7314/ APJCP.2015.16.13.5565

Zhu ML, Wang M, Cao ZG, He J, et al. (2012). Association between the ERCC5 Asp1104His polymorphism and cancer risk: a meta-analysis. PLoS One 7: e36293. http://dx.doi.org/10.1371/journal.pone.0036293 